\title{
On the Interpreter's Choices: Making hermeneutic relativity explicit
}

\section{MA Lin and Jaap van Brakel}

\begin{abstract}
In this paper, we explore the various aspects of hermeneutic relativity that have rarely been explicitly discussed: whether the interpreter likes it or not, he/she must make a large number of often implicit choices, which derive from the guidance or constraint originating from his/her background and situatedness. We refer to them as "choices" or "commitments" because in principle the interpreter can "choose" to be guided by other constraints. This idea differs significantly from the Gadamerian prejudices.
\end{abstract}

\section{Keywords}

Interpretation Theory, prejudice (Vorurteil), Comparative Philosophy, Chinese Philosophy, Hermeneutic Relativity

MA Lin

School of Philosophy, Renmin University of China (Zhe-xue-yuan), Av. Zhongguancun 59, Haidian District, Beijing 100872, China e-mail: lin.ma.2007@qq.com, malin2008@ruc.edu.cn

Jaap van Brakel

Hoger Instituut voor Wijsbegeerte, KU Leuven, Kardinaal Mercierplein 2, 3000 Leuven, Belgium

e-mail: Jaap.vanBrakel@kuleuven.be 


\section{On the Interpreter's Choices: Making Hermeneutic Relativity Explicit}

\section{INTERPRETATION ACROSS TRADITIONS AND HERMENEUTIC RELATIVITY}

We consider that comparative philosophy involves such a wide range of activities as translation, interpretation, and exposition of the conceptual schemes of an "alien" philosophical tradition in terms of the conceptual schemes of one's "own" tradition, as well as comparison of these conceptual schemes in a meta-language constructed by the interpreter. ${ }^{1}$ We assume that translation is always already interpretation. We take for granted that there is not just one interpretation of a certain texts (hence, our stance is pluralism, neither monism nor relativism). The discussion of hermeneutic relativity in this paper purports to show that there are many kinds of reasons why interpretations of different scholars may differ and opinions on what is a better interpretation can never converge. Of course, particular interpretations may loose or gain their plausibility over time.

Elsewhere we have proposed a theory of interpretation, which can be called a hermeneutic theory, with ingredients from both continental (for example, Gadamer) and analytic philosophy (for example, Davidson). ${ }^{2}$ Under the influence of Gadamer and Heidegger, hermeneutics has taken on two rather different meanings in Western philosophy. For them, hermeneutics is not merely a method to be favored in the humanities, but a feature of all human activity. Nineteenth century German hermeneuticians (Dilthey, Rickert, Schleiermacher, Windelband) and twentieth century well-known philosophers (Apel, Gadamer, Habermas, Hirsch, Rorty) all give somewhat different definitions of hermeneutics. One may find even more definitions in the secondary literature; for example: decoding meanings; a process of translation which transcends the literal; empathy with the creative personality of the author; the sort of understanding one is confronted with when interacting with other human beings or their intellectual products (such as texts and artworks). We agree that "interpretation" is a feature of all human activities (including interaction with other

\footnotetext{
${ }^{1}$ A conceptual scheme is a cluster of concepts. Because of the holism of concepts, a concept is, strictly speaking, already a conceptual scheme. We prefer the word "tradition" where other scholars may use the word "culture."

${ }^{2}$ See Ma and van Brakel (2016a, 2016b). In the latter publication we have indicated in detail where we agree and where we disagree with Gadamer (and Davidson).
} 
"traditions"). Hence, we use "hermeneutics" in the broad sense of "theories of interpretation," including reflection on the presuppositions of such theories. We consider the expressions "theories of hermeneutics" and "theories of interpretation" as interchangeable.

In earlier work we have discussed a number of necessary presuppositions of interpretation (Ma and van Brakel 2013, 2016a), for example:

1. The interpreter must presuppose the "existence" of mutually recognizable human practices or forms of life (Ma and van Brakel 2016b).

2. The interpreter must assume that all general concepts in all traditions are family-resemblance concepts (Ma and van Brakel 2016c). ${ }^{3}$

The latter is the basis for the possibility of the extension of family-resemblance concepts and the choice or construction of quasi-universals (van Brakel and Ma 2015). Our notion of quasi-universal is different from all other uses of the phrase in that: (1) Quasi-universals are family-resemblance concepts. (2) Quasi-universals belong to the meta-language the interpreter is developing. (3) They are working hypotheses; in other words, they are revisable as a consequence of the continuing process of interpretation. (4) They fulfill a necessary role in interpretative practice. Without assuming a large number of quasi-universals, interpretation across traditions is not possible. (5) Data and background underdetermine the choice of quasiuniversals in any particular case. (6) A quasi-universal connects conceptual schemes from a limited number of traditions, for example (cluster around) $z h i$ 知 $\Leftrightarrow\{$ (cluster around) know*\}, has two sides, in English and Chinese respectively. ${ }^{4}$ The familyresemblance concept $z h i$ can be extended to cover features of know* and similarly for extending know* to cover features of $z h i^{5}$

\footnotetext{
${ }^{3}$ Our notion of family resemblance should be distinguished from other versions of Wittgenstein's notion of "family resemblance" and notions such as "vague concepts." Familyresemblance concepts in our sense have no essences (or "cores"), no strict borders. This holds for concepts at all levels: everyday concepts such as green and qing 青, philosophical concepts such as emotion(s) and qing 情, philosophical categories such as form(s) of life and dao 道, and meta-concepts such as thing and $w u$ 物.

${ }^{4}$ The symbol $\Leftrightarrow$ means "stands in a family resemblance relation with." The symbol * indicates that all words in English with the same "root" are included; for example, know* refers to knowing, knowledge, knowledgeable, know-how, know-that, know-to, know-about, etc.

${ }^{5}$ We stress that the quasi-universal is not the same on the two sides. We do not believe in the possibility of "an unexpected osmosis of concepts" (Chakrabarty and Weber: 233).
} 
In addition to these and other "transcendental" conditions of possibility, there is the unavoidable constraint that in the current epoch of globalization and the ensuing regimentation of the languages of the world relative to the dominant language(s) of the center, the process of globalization (following the aftermath of colonialization) drastically undermines the possibility of interpreting texts from ancient traditions. ${ }^{6}$ Another constraint (as well as "guidance") of interpretation is hermeneutic relativity, which is the subject of this paper. The phrase "hermeneutic relativity" has been normally associated with physical theories and has rarely been used by other authors in comparative philosophy. It was introduced (and used) in Ma and van Brakel (2016a). Our notion of "hermeneutic relativity" can be seen as an extension, with significant revisions, of Gadamer's notion of Vorurteil and Heidegger's "Vorbegriff." Hermeneutic relativity refers to various choices and constraints of the interpreter (for example, beliefs concerning the best way of doing philosophy, what criteria are to be used to evaluate competing interpretations, etc.). The interpreter cannot completely eliminate the guidance and constraint originating from his/her "background." Hermeneutic relativity is the major cause for the variation of competing interpretations (as elucidated in this essay).

Gadamer's notion of prejudice (Vorurteil) is well known (Gadamer 1989: chapter 4). ${ }^{7}$ Some "prejudices" are often acknowledged; but there also "prejudices" that are rarely mentioned (for example, commitment to particular epistemic virtues; see §6). Bias or prejudice (i.e. hermeneutic relativity) is often considered as a disturbing factor that one can avoid, at least in principle. It is not sufficiently realized that it is neither possible to find out what all the Vorurteile are, nor to avoid prejudices completely. Smid says that, although biases cannot be avoided, "they can be dealt with responsibly and even productively" (Smid 2009: 4). But it is not clear how one would live up to this demand. Smid also speaks of "the undue influence of one's cultural background, where 'undue' means uncritical, excessive, and/or distortional" (91, emphasis original). Again criteria of what is undue, uncritical, excessive, distortional are left in the air.

\footnotetext{
${ }^{6}$ See Ma and van Brakel (2016a: chapter 8).

${ }^{7}$ Vorurteil: A judgment that has already been (tacitly) made before interpretation starts. Hermeneutic relativity may also be associated with the Gadamerian notion of "historicallyeffected consciousness."
} 
In the present paper we discuss the many aspects of hermeneutic relativity (which have rarely been explicitly discussed): whether the interpreter likes it or not, he/she must make a large number of (implicit) choices, which derive from the guidance and constraint originating from his/her background and situatedness. We will refer to them as "choices" or "commitments" because in principle the interpreter can "choose" to be guided by other constraints. Here is a list of such choices:

1. The choice of goal of investigation, including choice of texts to be studied and the context of these texts $(\S 2)$;

2. The choice of interpretative context, for example, the choice to assume a particular fundamental difference between European and Chinese thought $(\S 3)$;

3. The commitment to a particular philosophical method or approach; that is, choice of (background of) favored theory of interpretation $(\S 4, \S 5)$;

4. The choice of criteria for the evaluation of competing interpretations (§6);

5. The commitments with respect to the notion of language $(\S 7)$;

6. The choice of what is presupposed being shared across traditions $(\S 8)$;

7. The choice of quasi-universals, which in the current practice of comparative philosophy is most hidden in the choice between alternative translations (§9). In an afterword $(\S 10)$ we present some suggestions (not worked out in full in the present paper) concerning the possible relevance of Zhuangzi's remarks concerning shifei 是非. These remarks may help addressing the apparent irresolvability of clashes between different interpreters concerning their often implicit and hidden commitments with respect to hermeneutic relativity.

\section{THE CHOICE OF AIM, TEXT(S) AND CONTEXTS}

Any kind of investigation starts with the choice of the subject of investigation and its focus: the goal of the investigation, the choice of text, and the delimitations of the context of the text. ${ }^{8}$ This choice may seem to depend on the "free choice" of the investigator, but it is constrained by what her/his peers would think of these decisions and by her/his history of education/learning.

\footnotetext{
${ }^{8}$ The choice of the intended audience may be considered to be part of the choice of the goal of investigation.
} 
If the goal is to represent the "old" conceptual schemes in a modern language, the internal and historical context of the text would be in focus and one may speak of "historical reconstruction." If the goal is to show how classic texts can contribute to the present philosophical discourse, one may speak of such an investigation as "rational reconstruction.",

Sometimes it is claimed that one can decontextualize a text and evaluate its contribution to some present philosophical issues without paying attention to the historical context. However, the stage of rational reconstruction remains dependent on the historical reconstruction. ${ }^{10}$ In the sequel we restrict ourselves to "choices" that are made in the "earlier" stages of interpretation, that is, the stage of historical reconstruction (or textual interpretation). ${ }^{11}$ However, almost anything we say will apply to philosophical extension of what is found in the text as well.

There are few commentators left who focus on "authorial intention." But there is still disagreement among commentators as to whether "we" can understand "them" better than "they themselves." It is true that "we" are better placed to see how X fits into its times (and the times before and after). On the other hand, "our" distance to the texts may be so large that "our" understanding would almost certainly be quite different from "their" understanding.

Underdetermination of interpretation already starts at the level of choosing the text's "identity." In addition, there can be disagreement on what to take as context and what is important in the context. How much of the prevailing forms of life and scholarly discussions should be included? How many languages can the interpreter read?

\footnotetext{
${ }^{9}$ In distinguishing between historical and rational reconstruction, we follow SHUN Kwong-loi (2009). Another option is to make a distinction between retrospection and prospection; that is, an archeology of the historical context in which the text was created and the ongoing reception of a text (Makeham 2006:101).

${ }^{10}$ In the case of relatively recent texts in one tradition, abstraction of the historical context might be admissible; for example in the case of Kant's On Perpetual Peace. In the latter case, the historical context is left for the intellectual historian.

${ }^{11}$ Historical reconstruction coincides with "textual analysis," including parsing, analysis of the connotations of key terms, an investigation into the intellectual climate of the times; relating the text to other texts; seeking to understand the experiences and concerns of the author (Shun 2009, 2016).

${ }^{12}$ For a relevant example, see the very different responses to the proposal of Graham to move a small part from the beginning of chapter 14 to chapter 2 of the Zhuangzi (LIN Shuen-Fu 2003: 276-279; Billeter 1998: 6).
} 
Nylan discusses several examples of how some scholars display insufficient awareness of manuscript culture: composite texts, issues of authors and compilers, problems concerning influence, citations from other texts, spotting copious verbiage, scroll-unit, latter-day reconstructions, fake sources, role of debate/education, class and status identities, etc. (Nylan 2016). Seeing Nylan's many examples of faulty translations due to neglecting the historical context, there seems to be room for a lot of improvement in translating classical Chinese texts.

As pointed out by LI Xiaofan in a discussion of translations of the Liezi, a particular source text tends to become fossilized because the purpose of translation requires that the text be singular rather than plural; fixed rather than fluid (Li 2015). Li emphasizes that translating in a language that is closer to the original text's language is not necessarily more precise or faithful than translating in a language that is radically different from the original language. It may happen that a modern Chinese translation misleads readers by suggesting that ancient connotations of particular characters/expressions are the same as in modern Chinese.

Before leaving the issue of the text-cum-context behind us, we want to draw attention to the confusing use of the phrase "on its own terms." This phrase seems to originate with Hall and Ames, ${ }^{13}$ but it has been used by a large number of other scholars, including Maraldo, Neville, Rosemont and Shun Kwong-loi. This phrase has also popped up on internet websites such as the Asia Network and Warp, Weft, and Way. Would such a thing as interpreting Chinese philosophy "on its own terms" be possible? We need to face the music: Nowadays, it is not possible anymore to avoid dependence on Western philosophy, because globalization has brought about ensuing large numbers of neologisms in all modern languages. It is not unreasonable to suggest that, in some respects, modern (philosophical) Chinese is closer to modern (philosophical) English than to classical (philosophical) Chinese.

Using the notion of geyi 格義 as a generic interpretation model, one could rephrase "on its own terms" by saying: "One should use the ge 格 (standard?) of tradition X to interpret its $y i$ 義 (meanings?).” However, one should not forget that if the interpreter is advised to interpret X's yi using X's ge, the first thing the interpreter

\footnotetext{
${ }^{13}$ Ames uses this expression five times in a recent interview (Tan and Huang 2015). Ames also uses it in the title of his article "Indigenizing globalization and the hydraulics of culture: taking Chinese philosophy on its own terms" (Journal of Globalizations, vol. 1, 2004).

${ }^{14}$ On geyi 格義 see Ma and van Brakel (2016a: last section of chapter 7).
} 
has to do is to interpret X's ge (which is a yi for the interpreter) in terms of his/her ge. Hence, a tradition is never interpreted on its own terms.

An interpreter always remains tied to his/her language. Setting Chinese concepts among their "own" concepts has to stop somewhere. Qing 情 can be explained, for example, in terms of xing 性 and other Chinese concepts. However, eventually, the connection with the interpreter's own language has to be made (or, the connection between classical and modern Chinese has to be made). For example, assuming the interpretation is achieved in English, by establishing such quasi-universals as \{xing $\Leftrightarrow$ [human] nature $\}$. Of course one may set out to explain, say, xing "on its own terms," but this explanation again depends on assumed quasi-universals that connect classical and modern languages.

Littlejohn raises the slogan "let a text speak for itself" (Littlejohn 2016: 75-85). ${ }^{15}$ He is right to argue that one must appreciate the structure of the text and to let the text "lead" the interpretation (as in a dialogue). However, "let a text speak for itself" is subject to the same criticism as the use of the phrase "on its own terms," because it suggests that one can avoid hermeneutic relativity. Littlejohn notices the double-sided reviews of Ames and Hall's translation of the Daodejing as both letting the text speak for itself and as not being "faithful" to the text (76), that is, not letting the text speak for itself. Littlejohn concludes: "Some conventional translations are yet more illuminating than those [Ames] provides" (78). Nevertheless, he does not explain why conventional translations are more illuminating (because they are more familiar?). In our opinion, "standard translations" authorized by the "tradition" cannot claim to be the last word. Such an idea presupposes that "final" interpretations can be reached in comparative philosophy, which is not possible.

Ames and Rosemont list about twenty-five examples, which, according to them, have often been translated in a distorting way (Ames and Rosemont 1998: 311), for example, tian 天 is rendered as Heaven and lei 類 as category. Their proposed translations deviate significantly from "the tradition." Our stance is that there is no fact of the matter of how, say, lei should be translated into English. If lei is a central concept in an investigation, it could be best left untranslated. When this is not

${ }^{15}$ An alternative expression by Littlejohn is: "faithfulness to the text as it is in itself" (76). Littlejohn's focus is not "new." Gardner ascribes to ZHU Xi the view: "allow the text to speak for itself" (Gardner 1990: 46). The phrase has been used in many contexts, in the first place in letting the Bible speak for itself. 
possible, for example in full-text translations, we advocate that a glossary (or a series of notes) be added, where the meaning nuances of certain characters can be discussed. This will give the reader a reasonable idea about the "distortion" caused by any translation.

\section{THE CHOICE OF THE INTERPRETATIVE CONTEXT}

In addition to the choice of text and context, the interpreter may be influenced by, even committed to, a particular overarching context; that is to say, general assumptions concerning the overall similarities and differences of Western and Chinese thinking. Many "dichotomies" have been proposed to interpret such a difference. For example, with reference to the Analects, Ni Peimin contrasts the Western method of theoretical reasoning with the gongfu 功夫 method, which starts from the actual situation the practitioner is in, and work toward "higher levels of artistic perfection" (Ni 2016: 130). A theory strives for completion, whereas it is in the nature of the gongfu method that it is never finished, because circumstances keep changing. We could add contrasts such as: intellect versus practice and embodiment; relevance of personal experience and self-cultivation versus (philosophical) truth; lifeguiding maxims as distinct from moral rules.

We follow Hall and Ames in calling a commitment to an overall difference between grand traditions a choice of interpretative context. They propose to distinguish between what they call first and second problematic (Hall and Ames 1995: 112-15). The first (classical Chinese) problematic is characterized in terms of analogical, correlative, or aesthetic relations; particular assumptions are: there is no existence of a single-ordered world; no final unity; no initial beginning. This problematic is a further development of earlier proposals in terms of correlative, associative, or coordinative relations (referring to Granet, Needham, Graham). The second (Western) problematic is characterized in terms of features such as: rational, causal, objective, uniform. They acknowledge that both "problematics" are present in both traditions, but in each tradition one form is dominant. The contrast between analogical and causal thinking could provide a means of bridging Western and Chinese traditions. This would help understand classical Chinese texts "on their own terms" (Ames and Hall 2003: xi). 
The terminology of first and second problematic was first introduced in Hall and Ames (1995), but the contrast already occurs in an earlier book (1987: 134-38), where they use the distinction between logical (or rational) and aesthetic order(edness). The former focuses on "pre-established pattern of relatedness," directing us "away from the concrete particular towards the universal." The aesthetic orders have no "obligatory recourse to ideal or principle" and begin "with the uniqueness of the one thing." Paul has criticized the contrast of logical and aesthetic order because this implies for him that Hall and Ames would thereby deny the universality of basic logical laws such as the principle of non-contradiction (Paul 1991: 119-121). However, we think that Paul is overreacting. ${ }^{16}$ Hall and Ames only speak of "logical order" as a contrast with "aesthetic order." They do not contrast the adjective "logical" in Paul's sense with "aesthetic." The contrast is rather that of "focus on universal" versus "focus on particular." Hall and Ames do not claim (or imply) that the aesthetic order is "illogical" (in Paul's sense). ${ }^{17}$ Paul uses the word "logic" in the sense of basic logical laws (law of contradiction, etc.). Hall and Ames use the word "logical" in a loose sense. For example, this loose use of "logic(al)" is apparent when Møllgaard accuses both Hansen and Ames of "subsum[ing] Chinese thought under an overarching logic” (Møllgaard 2005: 330). According to Møllgaard Hall and Ames’s "aesthetic order" would be an "overarching logic." Similarly, when Ames recently writes that $s h i$ 勢 is an aesthetic alternative to the logic of “things" (in Tan 2016: 44), one may perhaps disagree with his use of the word aesthetic in this context. However, it would be unreasonable to ascribe to Ames the view that shi 勢 is a logically inconsistent notion. ${ }^{18}$

Paul also argues that Hall and Ames's “wording would suggest a gap between 'Chinese' and 'Western' modes of thinking, much deeper and much more serious than it is actually possible to be" (Paul 1991: 77). Similarly, Martin, in a review of Hall and Ames (1987), wonders, "can there be two ways of thinking so very different?"

\footnotetext{
${ }^{16}$ What is more interesting than his critique of Hall and Ames is Paul's observation that Aristotelian/Fregean logic does not require presupposing a shared notion of truth. Logical laws can be formulated in terms of identity/diversity relations of/between concepts.

${ }^{17}$ Paul says that Hall and Ames "hold that the Lunyu is an example of aesthetical rather than rational or logical thinking" and that Confucius "does not acknowledge and endorse logical thinking" (Paul 1991: 76). But this is not true to what they say.

${ }^{18}$ Elsewhere Ames says we must accord with the principle of logical clarity (Ames 2011: 37).
} 
(Martin 1990: 503, emphasis original). ${ }^{19}$ Paul also leaves open the possibility that "the text is completely beyond comprehension" (73). However, if we want to assume that the other language is totally untranslatable despite repeated efforts, how could one know it was a language in the first place (and not random noises)? There can be no such thing as a completely untranslatable language. ${ }^{20}$

A more substantial criticism of Hall and Ames is that they insert assumptions deriving from American pragmatism or process philosophy, between themselves and the texts they aim to interpret. We concur with Frisina when he says: "Hall and Ames have managed to make their Chinese texts speak like American pragmatists" (Frisina 2016: 572). The same applies to them invoking process philosophy. Consider Ames saying "we suggest that the qi-cosmology of the world of the Zhongyong has some affinities with process philosophy" (Ames 2004: 290). The claim that process philosophy can be helpful for interpreting the Zhongyong should stand on its own. There is no need to add an overarching interpretative context.

We believe that placing too much emphasis on presupposed overall differences for the whole of Chinese and Western philosophy is misleading. Traditions are heterogeneous. Extant sources are limited. Some assumptions concerning an overarching context of interpretation (including trivial ones like differing time and place) cannot be avoided, but there is no need to give them undue emphasis; in particularly not if this involves using concepts from the Western philosophical tradition. Most scholars who assume significant overall similarities and/or differences between Chinese and Western philosophy/thinking present these similarities and differences in terms of Western concepts. ${ }^{21}$ Using Western concepts to characterize

\footnotetext{
${ }^{19}$ Smid points out that Hall and Ames's response to Paul and Martin was dogmatic; but he notes that in later exchanges, Ames shows an open mind to alternative perspectives (Smid 2009: 131-32).

${ }^{20}$ It is possible that not enough fragments of a language are available for interpretation. However, this does not "prove" the thesis of untranslatability. More fragments may be found, and archeological traces of the relevant form(s) of life may assist in interpretation.

${ }^{21}$ For example, Ames and Rosemont propose to translate zheng 正 as "correct conduct" and not "rectification"; and there are similar cases with other "conducts" (Ames and Rosemont 1998: 311). The revised translations might perhaps be better than the "received" translation, but the (pragmatic) notion of conduct is presupposed as a universal grounded in the Western concept of "conduct." One might even worry that the notion of human conduct in the work of Dewey and Mead is simply projected onto classical Chinese texts.
} 
"fundamental" differences runs the risk of transcendental pretence, as Hall and Ames themselves have pointed out. ${ }^{22}$

\section{THE CHOICE OF THEORY OF INTERPRETATION}

In the previous section we focused on commitment to an overall interpretative context (in particular the proposal of Hall and Ames), which tends to undermine the heterogeneity of traditions. In the present section we focus on commitment of the interpreter to a specific philosophical method or approach; that is, the choice of theory of interpretation.

What is usually hidden in the education and learning of investigators is the commitment to a particular way of doing/understanding philosophy. Using rather general labels (with the risk of undermining the heterogeneity of traditions), we may say that within Western philosophy this concerns primarily the choice between analytic and continental philosophy; rather divergent pragmatisms are also at play. In Chinese philosophy this concerns primarily the difference between Confucian and other schools of thinking.

More specific choices are of course possible. As a result of the impact of cognitive science on (analytic) philosophy, comparative philosophy has also been under its sway. A typical example is Slingerland (2016). These more specific choices change over time. The issue of transcendence attracts Western philosophers with a religious orientation. The "application" of deconstruction to Chinese philosophy is a recent phenomenon. For every new option one can ask: Does the theoretical approach which has emerged in the West under this or that banner lead us any closer to "the Chinese mind" (as if there is only one such mind)? In this section we discuss a few examples of disagreements concerning the "right" method for comparative philosophy to show that such debates would seem to be irresolvable. Of course we are not denying that scholars will have reasons why they think their commitments, say to analytic or continental philosophy, are relevant and useful for the comparative work they are engaging in. But these "reasons" may not be convincing for their colleagues.

Møllgaard characterizes “the 'philosophical turn' in American sinology” as a turn to analytic philosophy, as represented by Hansen, and neo-pragmatism plus process

\footnotetext{
${ }^{22}$ Transcendental pretence is part and parcel of the constraints derived from colonialization and the ensuing globalization. See for this notion Ma and van Brakel (2016a: chapter 8); see also $\mathrm{Wu}(2009$ : 74-75).
} 
philosophy, as represented by Hall and Ames (Møllgaard 2005: 321). This kind of sinology subscribes to "a naïve historical objectivism and has no speculativehermeneutic dimension" (334). As an alternative, Møllgaard advocates what he calls an "anti-philosophical way of reading" (321). One should follow Gadamer: to tarry (verweilen) with the text. What is required is: "reading in the emphatic sense." However, it seems to us that one cannot take for granted that "figures of thought" would out of themselves dawn on the reader, provided that one reads the text "in the emphatic sense" (335).

Both Hansen and Ames suggest that Møllgaard seems to believe that one can avoid Gadamerian prejudices and start from a tabula rasa. On the other hand, Møllgaard's anti-philosophical way of reading unique texts may actually fit Hall and Ames's description of the aesthetic order, which "discloses unique particulars" (Hall and Ames 1995: 134).

The difference of the respective approaches of Ames and Hansen, which Møllgaard lumps together as the (American) turn to theory, is apparent from Ames's review of Hansen (1992). According to Ames, Hansen simply assumes "with little qualification the truth $(s h i)$ of his own position, and the falseness $(f e i)$ of the aggregate of all rival interpretations" (Ames 1994: 559). Such criticism is even stronger in Hall and Ames (1995: 149-58). They have no doubt about placing Hansen in the camp of the second problematic, ascribing to him a monistic transcendentalism (as distinct from their own interpretative pluralistic pragmatism).

Whereas Møllgaard speaks of a turn to theory in American sinology, Roetz criticizes Hansen's "pragmatic turn in sinology" (emphasis added). In a section on hermeneutic considerations, he specifies the following necessary features of interpretation (Roetz 1993: 101).

1. The implicit background-presuppositions of the text, the uniqueness of its language, its historical embeddedness in specific, contingent, and alienated circumstances, which indeed are causally effective; 2 . The sense of the text, which is not comprehensible by an explanation of causes, but by understanding the reasons of the author; 3 . The validity-claims of the text-be it the claim to sincerity of poetic expression, or the claims to normative rightness and truth of philosophical writing.

Roetz considers the first item as a matter of studying causes and claims that Hansen is solely concerned with it and has completely neglected items 2 and 3. This seems to be true as far as the sincerity of poetic expression is concerned, because Hansen would 
consider this to lie outside the range of philosophy. ${ }^{23}$ As to Roetz's item 2, it is noteworthy that, throughout his text, Roetz translates the character $g u$ 故 as "reasons," which is disputable. Roetz charges Hansen of having ignored motivations (that is, reasons), but Hansen does ascribe motivations to literati such as Laozi and Mencius. ${ }^{24}$

Roetz criticizes Hansen's "scientific" approach. However, Roetz himself complies with analytic philosophy's central theses of precise meanings and isomorphy between languages when he criticizes Hansen's claim that no word or phrase in classical Chinese should be translated as tru*, by offering a long list of Chinese characters that "imply the claim to truth" (Roetz 1993: 96).

Allinson (2003), Ames, Møllgaard, and Roetz have all claimed their approach to be a hermeneutic one. Møllgaard opposes both Ames and Hall because of their alleged "theoretical" approach while presenting himself as the "true" follower of Gadamer. However, Ames' criticism of Hansen shows that Ames's pragmatism is on the hermeneutician's side. Hansen also reveals a pragmatic side when he argues that classical Chinese texts should be read as performative texts; with which Ames agrees (Ames 1994: 558). Ames includes postmodernism as part of the background of his approach, while Allinson strongly opposes signs of postmodernism. In our view, all comparative philosophers can be regarded as hermeneuticians because they are all involved in the interpretation of texts. What make them look so divergent are their varying "background/presuppositions." Thenceforth they have wide-ranging disagreement that often leads to semantic confusions.

There are many more disagreements that are related to a great variety of methods and theories of interpretation with different commitments. Our discussion only covers a small number of sinologists. ${ }^{25}$ A beginning Anglophone comparative philosopher would have to consider whether he or she favors the approach of Ames, Hall, Hansen, Møllgaard, or Roetz. Although debates between the adherents of different methods may make sense in practice, we do not think such disagreements are resolvable at the deep level of interpreters' hermeneutic relativity (see further $§ 10$ ).

\footnotetext{
${ }^{23}$ Hansen allows other kinds of interpretation such as literary interpretation, but they should be judged within the confines of another discipline that is not philosophy.

${ }^{24}$ See Hansen (1992: passim).

${ }^{25}$ Another relevant example is the "ongoing conversation" of Hall \& Ames with Neville concerning "transcendence" and other "metaphysical" notions. However, "despite over twenty years of discussion, they are still at an almost complete impasse" (Smid 2009: 167). See also Ames and Franke in Brown and Franke (2016).
} 


\section{CHINESE HERMENEUTICS}

In the Encyclopedia of Chinese Philosophy not much attention is paid to hermeneutics (Cua 2003). Opinions of contributors differ as to when we can say that Chinese scholars discussing the methodology of interpreting classical texts might be called hermeneuticians. For example, Han scholars are said to "share the same hermeneutical approach" (Chan in Cua 2003: 742). Christina Han refers to the NeoConfucian dispute concerning Zhu's poem "The Boat Song of Wuyi's Nine Bends" as "rigorous hermeneutic debates" (Han 2013: 66). However, according to CHENG Chung-ying, it is only with DAI Zhen 戴震 (1724-1777) that hermeneutics truly appears in China. Dai is "the world's first practitioner of philosophical hermeneutics" (Cheng in Cua 2003: 196).

In modern Chinese philosophy, invoking hermeneutics has become quite popular. ${ }^{26}$ Some scholars formulate their own version of hermeneutics with Chinese characteristics; for example, FU Weixun's creative hermeneutics and CHENG Chungying's onto-hermeneutics. Fu's hermeneutics attaches importance to the aspect of methodology, drawing inspirations from Buddhist and Daoist thought. Ontohermeneutics is born of a synthesis of Chinese intellectual traditions (especially the tradition related to Yijing) and Western philosophy.

It seems that most Chinese hermeneuticians follow Gadamer in taking (hermeneutic) experience and interpretation as something universal across traditions/humans. ${ }^{27}$ An influential example of hermeneutic universalism can be found in the work of Cheng who assumes that (the only one) metaphysical reality is both rationally accessible and intuitively experienced. Therefore, any interpreter can "seek an understanding in terms of the meaningful connections of basic notions of a given text, with both intended and factual references to a reality which one could also experience and appeal to independently of the text" (Cheng 2000: 33). That is to say, the reader lives, inhabits, and experiences the very reality that is textually represented

\footnotetext{
${ }^{26}$ For details of the history of "Chinese hermeneutics" in the latter half of the twentieth century see Pfister, in particular the copious notes in his introduction to a book supplement to the 2006 edition of the Journal of Chinese Philosophy entitled "Hermeneutical thinking in Chinese philosophy."

${ }^{27}$ LIU Xiaogan has criticized Chinese scholars for exclusively using "intellectualistic" hermeneutic methods while forgetting about society and self. See LI Yinghua (2010:368).
} 
(Ng 2007). ${ }^{28}$ However, it should be stressed that Gadamer's work is primarily concerned with the history of the Western tradition. Therefore it would seem that his authority does not suffice to claim the same experience of the same metaphysical reality for both "East" and "West" (and for everybody). Even if, in addition to a shared world, there is a shared metaphysical reality, it does not follow that experiences (and the ensuing conceptualizations) would be the same for all humans.

If we want to try to say something specific about Chinese "hermeneutics," as distinct from the history of hermeneutics in the Western history of ideas, we have to engage with the long history of textual interpretation from the Han dynasty onward. ${ }^{29}$ A landmark in this history is the work of ZHU Xi 朱喜 (1130-1200). The relevance of Zhu's methodological considerations, at least for the study of Confucianism today, is apparent from the work of such scholars as SHUN Kwong-loi, who presents his own methodology in tandem with that of ZHU Xi-except that Zhu's final focus is to understand $l i$ 理 (Shun 2016).

Some commentators have suggested that Zhu's dushufa 讀書法 (methods of reading) can be considered as a version of hermeneutics (Berthrong 2006: 145, Pan 2003, Shun 2016: 66, Gardner 1990: 42; Martinich and Xiao 2010). ${ }^{30}$ It seems that the following specific advice of Zhu (to his students) remains relevant to the methodology of good interpretation today:

1. Zhu has criticized commentators who "have given a far-fetched interpretation of the purports of the sages in light of their taken-for-granted daoli [一副當道理].” ${ }^{{ }^{3} 1}$ Interpretation would be distorted if interpreters read their own ideas into the text (Gardner 1990: 46). This could be compared, but not identified, ${ }^{32}$ with Gadamer's

\footnotetext{
${ }^{28}$ Another example of universal hermeneutics is Zhang Longxi's invocation of a blanket "universality of the hermeneutic phenomenon" in order to justify putting Western and Chinese sources "in a sort of critical dialogue" (Zhang 1992: xiii).

${ }^{29}$ Some commentators oppose associating Zhu's advice concerning reading and interpretation with (modern) hermeneutics; cf. literature reviewed in ZHENG Shuhong (2017). As explained in $\S 1$ we use a broad (vague) notion of hermeneutics, not something associated with a particular philosopher such as Gadamer or Heidegger.

${ }^{30}$ Concerning Pan (2003), cf. Ma (2004).

${ }^{31}$ All the citations in these paragraphs are from Zhuzi yulei (Zhu Xi's Classified Conversations), the edition of LI Jingde 黎靖德 (Li 1986); the juan numbers refer to the "chapters" in the original edition. Daoli 道理: "the Way and the Principle" or "the Principles of the Way." (juan 137). English translations from the Zhuzi Yulei are by Ma Lin.

${ }^{32}$ The text of Pan and Peng suggests that Zhu Xi used the phrase xianru zhi jian [先入之見, “preconceptions"] (Pan and Peng 2006: 139; referring to juan 139). However, this phrase does
} 
notion of prejudice and with transcendental pretence. The interpreter should have a receptive mind (xuxin 虛心), an attitude of jing 敬 (respect, reverence), and should be unbiased and receptive, not imposing one's own opinions (Shun 2016: $66)$.

2. On the one hand, with respect to the concrete process of interpretation, Zhu stresses the importance of the meaning of detailed parts. On the other hand he stipulates that understanding the integral meaning of the whole text is the purpose of comprehending the classics (Pan 2003: 107).

3. Interpretation should start with thorough textual analysis, which includes careful parsing of phrases and sentences, reading one character at a time. This aspect has often been neglected by hasty students.

4. Zhu stresses the relevance of the notion of "layers of meaning" (of a text). For example, he uses Zhuangzi's story of cook Ding 丁 to argue that one cannot just assume being faced with a text with a unitary and plain meaning. One needs to decipher the meaning, and, analogous to dissecting an ox, to master the lines or veins of the text. This could be called hermeneutics with Chinese characteristics. ${ }^{33}$

5. One should question the claims of scholars who have come up with different interpretations of a particular text (Pan and Peng 2006: 137-39). Hence, the commentarial tradition should not be neglected and should be approached critically in the study of the classical texts.

6. Zhu stresses the importance of methodological doubt; a willingness to doubt, "not just the views of others but one's own view as well" (Gardner 1990: 46). ${ }^{34}$

Zhu's instructions to his students as to how to read the text of the classics may be

not occur in Zhu's text. The relevant phrase is congqian suojian从前所见: “学者不可只管守 从前所见, 须除了, 方见新意。如去了浊水, 然后清者出焉。”'Scholars should not just adhere to what they have understood/seen in the past. Only when they abandon it can they obtain new ideas. It is as if only when the muddy water is dispensed can there be clear water" (juan 11).

${ }^{33}$ The passage concerning cook Ding: "In the beginning, a scholar sees only a single piece of text; later on he sees it as three or four leaves (parts), then a dozen parts; only by this time has he made advance" (juan 3). On layers of meaning Zhu Xi advised his students: "The words of the sages have layer upon layer. One should read them from within their depth. If one only wants the skin [pifu 皮膚] [of their words], one would make mistakes. Only when one steeps oneself into the words can one acquire something" (juan 10).

${ }^{34} \mathrm{Cf}$. 群疑并兴, 寝食俱废, 乃能骤进 “only when there occur a multitude of doubts ... can one gain a big step forward" (juan 10). 
compared with Gadamer's tarrying with the text (verweilen) ${ }^{35}$ However, apart from Zhu's focus on interpretation of the meaning of the classics in the service of understanding $l i$ 理, ${ }^{36}$ an important difference with many variants of Western hermeneutics is that Zhu was opposed to "empathy": "How could the interpreters know what the sages thought in such a different context?" (Pan and Peng 2006: 139). ${ }^{37}$ According to Zhu, the interpreter should examine his/her involvement in daily events (in light of the texts).

Invoking empathy is common in the phenomenological tradition, but Gadamer directs the focus to the subject matter of textual interpretation. As he says in an often cited passage: "To understand what a person says is ... not to get inside another person and relive his experiences" (Gadamer 1989: 385). In contrast, CHENG assumes a strong sense of empathy across traditions in his onto-hermeneutics. As he writes, "knowledge would be a matter of this congruence of mutual feelings reached from this reciprocating process of feeling projection and feeling response" (Cheng 2000: 42). In our view, it is true that interpretation would not be possible if one cannot rely on some sort of quasi-universal for the idea of Mitsein and/or Mitzutun, ${ }^{38}$ but it is too universalistic (or too simplistic) to assume that the description of this quasi-universal can be given independently of time, place, and language.

The case of ZHU Xi suggests that if we want to construct hermeneutics as a quasiuniversal, ${ }^{39}$ we must include the goal of interpretation (cf. §2) as well as its relevance to contemporary philosophy and, most importantly, to the question of how to live our lives. According to Zhu, scholars should examine daily events for themselves in light of the classical texts to come to understand the original intention of the sages; and thus making the words of the sages relevant to their own daily lives. This aspect is not ignored in Western hermeneutics. Gadamer often stresses applicatio, ${ }^{40}$ but his

\footnotetext{
${ }^{35}$ See juan $10-12$ in Zhuzi yulei.

${ }^{36}$ 理得, 則無俟乎經 “We no longer need to stay with the classics once we have mastered $l i$ ” ( $\mathrm{j}$ juan üan 11).

${ }^{37}$ On this point, Shun seems to have a different view. He points out that Zhu presupposes affinity between experiences of the sages and experiences in his own time (Shun 2016: 66).

${ }^{38}$ That is: being-with and/or doing something together. See for these notions Ma Lin (2014).

${ }^{39}$ In the present case a quasi-universal might be \{hermeneutics $\} \Leftrightarrow\{$ kaoju 考据 $\}$. Quanshi 詮釋 is a modern word, which does not occur in older texts.

${ }^{40}$ The notion of applicatio is a central concern for Gadamer's hermeneutics: how is what is being said in the text applicable to one's society and also to oneself. Some of Gadamer's commentators have suggested that one can make oneself conscious of the negative and positive sides of one's tradition (in order to overcome undesirable prior beliefs). Strictly
} 
discourse is restricted to interpreting classical texts from the Western tradition (just as Zhu's discourse is restricted to interpreting classical texts from the Confucian tradition). Some people may take this restriction as granted and unproblematic. However, we may also take this as a requirement that comparative, Chinese, or any other kind of philosophy (or other intellectual pursuit) should be relevant for how to live our (human) life.

As an "appendix" to this section we make a few critical remarks concerning Allinson's contribution concerning "intercultural hermeneutics," which is the sole full-length article on hermeneutics in Cua's Encyclopedia of Chinese Philosophy. ${ }^{41}$

Allinson's brief "definition" of intercultural hermeneutics is: it is the study of the complexities of understanding "any message passed between cultures" (Allinson 2003: 315). ${ }^{42}$ His more detailed "definition" sketches the hermeneutic approach of the interpreter in terms of three steps. First, "one must be capable of understanding the categories of understanding of one's own culture." Second, the interpreter must understand the categories of the other culture. This stage cannot be reached if the interpreter has not first "become one" (that is, being assimilated) with the tradition being interpreted. Hence, what is required is "fluency in at least two cultures and a capacity to transcend the limitations of each culture ... interpreting each culture for the other" (316-17). Third, the resulting intellectual products can be taken as a standpoint that gives "a greater understanding" of both one's own and the alien culture. In this "most meaningful step," one chooses "the best from both traditions, forging a new meaning that is a hybrid of both traditions and did not exist beforehand in either tradition" (319).

Allinson's transcending overarching comparative philosophy is illustrated in his own research; for example, a "transcending" interpretation of the story of Zhuang Zhou and the butterfly. Allinson seems to assume that there is only one way of transcending the two traditions. However, he does not offer any explanation as to

speaking this is not possible, because hermeneutic relativity cannot be separated from the interpreter's place and time; there is no fact of the matter with respect to one's own background. Negative and positive judgments are relative to this background.

${ }^{41}$ Allinson only considers the interpretation of Chinese philosophy by Western scholars and says that he cannot address the equally interesting question of the interpretation of Western philosophy by Chinese scholars (319). This suggests that his hermeneutics does not intend to have universal scope.

${ }^{42}$ Allinson's choice of the word "message" (and "data," and "decipher" as well) is somewhat infelicitous. A better phrase (later used in his essay) would be "intellectual products." 
what the criteria are for "greater understanding" or of how to establish the "limitations" of a tradition and "transcend" these limitations. ${ }^{43}$ It seems that Allinson assumes that in a certain unexplained manner the interpreter could construct an ideal meta-language in which the interpreter can adjudicate what is best in both traditions.

\section{THE CHOICE OF STANDARD OF EVALUATION}

Interpreters have to assume a standard of evaluation for their work. We call these standards "epistemic virtues." Epistemic virtues are an important factor determining why one interpretation or theory is chosen and regarded as "better" than other interpretations. Epistemic virtues are values (Putnam 2002).

In Western discourse the notion of epistemic virtues is closely related to the conceptual schemes around know* and tru*. It is not uncommon in comparative philosophy to take the notion of know* for granted in the meta-language. For example, Jenco argues that, by using Chinese methods, one can become more familiar with differences. Thus one can "accommodate new practices and ideas circulating elsewhere", which would provide unexpected forms of knowledge (Jenco 2016: 273). But who is to judge whether Chinese methods are "relevant, useful, or illuminating" (282)? Throughout Jenco sticks to a fixed (Western) notion of "knowledge."

When $z h i$ 知 is not a synonym of 智, it is usually translated as either know* or understand*. That know* and understand* are alternative possibilities of translating $z h i$ is apparent from many passages in classic works. From the perspective of English one might say that the meaning of $z h i$ is a hybrid concept (it could mean either know* or understand* or both). If there is no time to carefully construct a quasi-universal (see $§ 9$ ), the best thing may be not to translate the Chinese character that is central to the commentator's argument. ${ }^{44}$

Many translators seem to be biased towards translating zhi as know*. See for example Watson's translation of the Zhuangzi. On almost all occurrences of zhi,

\footnotetext{
${ }^{43}$ In order to combat the threat of an "anything goes" relativism or postmodernism, Allinson feels obliged to use such phrases as "true intelligibility", "to make sense truly", "genuine understanding" (emphasis added). Presumably, using words such as "truly" or "greater understanding" presupposes universality of a fixed set of epistemic virtues (cf. §6).

${ }^{44}$ It is not uncommon for a comparativist to change his/her mind from one possible translation to another and finally settling for leaving the (crucial) character untranslated. See for example Rosemont as to the (un)translatability of Confucian ren 仁 (Rosemont 2012: 1720).
} 
Watson translates it as know*, although often understand* would make equal sense. For example: ${ }^{45}$

三子之知幾乎 The knowledge [understanding] of these three was close to perfection.

是惡知禮意! "What does this man know [understand] of the meaning of ceremony?"

知是非之不可為分 He knows [understands] that no line can be drawn between right and wrong.

and numerous similar cases in the Zhuangzi and in translations of other texts.

Following Hall and Ames (1987), Rosemont has suggested translating zhi as "realiz*" instead of know* because know* is associated with "knowledge that," whereas "realiz*" entails "making real" in the sense of "knowing how, knowing about, knowing to" (Rosemont 2012: 47). We do not agree, because we consider that it is better not to associate one's terminology in one's meta-language with modern philosophical discourse. The meta-language should be grounded in the "ordinary" (everyday, colloquial) language. ${ }^{46}$ The use of know* in colloquial English is not thought of specifically as "justified true belief." Know* in ordinary English is more similar to the classical Chinese zhi than Western (analytic) philosopher's use of know*.

To justify the quasi-universal zhi/know* we suggest that, ultimately, justification of inquiry is entrenched in two requirements: First, it should fit experience. Second, it should cohere with earlier results of inquiry. ${ }^{47}$ There are no general, let alone strict, criteria for how "fitting experience" and "earlier $z h i$ 知" is to be concretized in particular cases. Whether vague criteria of fitting, experience, etc. are or are not met is ultimately a matter of consideration and contestation among groups of people invoking maxims that are not grounded in scientific discourse, a contestation for which there are no rule-governed resolutions or compromises.

We suggest that epistemic virtues could be ordered in six groups: empirical adequacy (faithfulness to the data: text, observations, "facts," etc.); coherence (logical consistency, consonance with other knowledge/zhi and contexts, hermeneutic circles between levels of abstraction; scope (comprehensibility, exhaustiveness); pragmatic

\footnotetext{
${ }^{45}$ Cited from chapters 2, 6, and 17 of the Zhuangzi.

${ }^{46} \mathrm{Cf}$. Shun for a similar suggestion (Shun 2009: 474).

${ }^{47}$ Elsewhere we have argued that $\{$ fit* $\Leftrightarrow y i$ 宜\} can be a suitable quasi-universal to order the discourse concerning the "right" or "fitting" interpretation or theory.
} 
aspects (simplicity, clarity, being informative, ${ }^{48}$ being illuminating; social criteria (reflection on tradition, respect for alternative hypotheses, impartiality, appropriateness); metaphysical concerns: simplicity, ${ }^{49}$ aesthetic qualities, accounting for the ontological heterogeneity or homogeneity of the subject of study). Anybody reflecting on this list would soon conclude that there is no simple rule for deciding whether a particular interpretation meets which epistemic criteria (and, in particular, how it compares with other competitive interpretations)..$^{50}$

Concrete examples of debates involving epistemic virtues include: Mozi's three tests/standards (biao 表) understood as criteria for evaluating teachings, policies, or claims in general; Roetz's proposals for validity criteria in pre-Han times (Roetz 1993); standards of evidence as used by ancient Chinese ministers when presenting their views to the ruler (Olberding 2012). However, for some concepts used in the list of epistemic virtues, one may not easily find a suitable quasi-universal. For example, "facts," or "true to the facts," notwithstanding its popularity in the current academic arena, is not a universal, and it is difficult to construct a fruitful quasi-universal related to it. Today, "facts" is a left-over concept from late nineteenth century positivism. As late as Sima Guang 司馬光 (1019-1086), debates at Chinese courts did not invoke any clear notion of "facts" (Olberding 2012: chs. 7-8). Therefore, such characters as $s h i$ 實 should not be translated as "facts" or "truth." 51

As an example of a concrete proposal for epistemic virtues, consider the famous late nineteenth century Chinese translator YAN Fu 严复 (1854-1921). He specified three criteria for "good" translation: $x i n, d a$, and ya (信达雅), that is, fidelity (or faithfulness), comprehensibility (fluency, expressiveness), and elegance. A good translation of these three "golden principles" is difficult, but they are easily recognizable as epistemic virtues that are relevant to translation. Faithfulness can be

\footnotetext{
${ }^{48}$ We follow van Fraassen in considering being informative/explanatory as a pragmatic virtue.

${ }^{49}$ Note that we have listed "simplicity" under pragmatic as well as metaphysical criteria. There is little consensus on its supposed meaning and relevance.

${ }^{50}$ Our favorite list of epistemic virtues (applicable to both science and the humanities) is derived from Goodman's proposal: fitting in with the rest of knowledge (tradition, inertia, structural coherence), being attractive (initial credibility, providing understanding, future value, usefulness, relevance, simplicity), increasing our understanding of all interpretations, theories, stories (Goodman 1978: 19).

${ }^{51}$ According to Olberding (2012: 173; ch. 5), in an address an ancient Chinese minister would not "prove some point," but rather suggest a morale, a general principle for making a decision.
} 
classified under empirical adequacy; comprehensibility is a kind of coherence or "fitting in"; and elegance is an aesthetic quality. ${ }^{52}$

Coherence (within a text, with the cultural-historical environment, with "the tradition", etc.) is perhaps the most often invoked epistemic virtue in comparative philosophy. ${ }^{53}$ For example, Ziporyn's sophisticated interpretation of $l i$ 理 as a "second-order coherence between found coherence in the world and coherent clusters of human evaluation" may be seen as theoretical background for coherence being considered as a kind of fitting (together) (Ziporyn 2013: 27-28). In a different context, Hansen objects to the idea that coherence be sought with a specific text or a single philosopher (Hansen 1992: 266-68). According to him, the interpreter's task is to give a coherent account of the beliefs of the community of the philosopher being interpreted. Should the requirement of coherence be applied to a specific philosopher, to a specific text or to the beliefs of the philosopher's community? Our answer is that there is holism across the board. As the examples of Ziporyn and Hansen show, even such apparent universals as "coherence" can mean very different things to different interpreters.

The epistemic virtue of scope is often presupposed, but not often mentioned. An exception is the work of Neville. In Smid's detailed review, Neville (1995) is often cited as stressing the importance of the scope of a theory of interpretation, for example: the "best theory" should be "broad enough"; it should cover "all of reality" and "registers as much as possible the available phenomena" and the "full breadth of possible experience" (Smid 2009: 150-4, 167, 173). The notion of scope is rather selfevident with respect to the many interrelated physical theories. In comparative philosophy, how to evaluate scope would seem to depend on the subject of investigation.

The examples in this section illustrate that epistemic virtues have no precise definitions, and, more importantly, they may conflict. There is no single set of

\footnotetext{
${ }^{52}$ Contemporary translation theorists in China continue to draw on Yan Fu's proposal, modifying it in various ways. According to CHAO Yuen Ren both elegance and fluency can be overruled by fidelity (Chao 1969: 109). In the 1990s, Jin Di modified Yan Fu's xindaya by changing $y a$ to shenyun 神韵 (poetic charm, spirit); see Ma (2007). PENG Ting-ting argues that the most important of Yan Fu's three criteria is $d a$, the one that is least often discussed (Peng 2015).

${ }^{53}$ Almost all the scholars mentioned in the list of references at the end of this paper, at one point or another, in passing or with more discussion, use the notion of coherence to indicate a positive feature of an interpretation.
} 
epistemic virtues that characterize all sorts of "good" $z h i$. There are neither universal nor domain-specific rules as to how to weigh different virtues when they conflict. The choice of epistemic virtues and in particular the balancing/weighing of conflicting ones contributes to underdetermination of interpretation. A commitment to particular epistemic virtues cannot be avoided. Our pragmatic suggestion is that faithfulness, coherence and scope are epistemic virtues that are relevant to every type of interpretation (including poetry and science). However, interpreters will differ not only in the specification of these epistemic virtues and their commitment (if any) to virtues from the pragmatic and/or metaphysical cluster, but also, in particular, in their judgment concerning how to weigh the relevance of different virtues in a particular context or inquiry (quan 權).

\section{PRESUPPOSITIONS CONCERNING THE NOTION OF LANGUAGE}

In this section, we summarize some important features of commitments with respect to language bearing on hermeneutic relativity. The major choices with respect to commitments to the notion of language can be divided into three groups:

1. commitment to either an ideal language or an everyday language as methodological tool and final "arbiter" (cf. our discussion of zhi/know*);

2. views with respect to classical Chinese and to the issue of linguistic relativism (Sapir-Whorf hypothesis); $;^{54}$

3. choice of meta-language, including the choice of quasi-universals (see §9).

We have opposed the ideal language assumption and have suggested replacing it with a commitment to ordinary or everyday language and with the necessity of assuming family-resemblance concepts. ${ }^{55}$ Any discussion about artificially constructed ideal languages is embedded in a natural language. Suppose analytic philosophers and continental philosophers both develop an ideal language for conducting comparative philosophy. When they meet, they would still have to use an "ordinary" natural language such as Chinese or English as a meta-language to discuss their respective ideal language proposals.

${ }^{54}$ See Ma and van Brakel (2016a: 32-39).

${ }^{55}$ See Ma and van Brakel (2016a: chs. 2 and 4). Frege specifies that an ideal language should be objective (individual and poetic aspects are eliminated), exact (each expression has exactly one reference and one sense), structured or compositional (the reference and sense of each expression can be "calculated" from the reference and sense of its constituting parts), and each sentence is either true or false (Frege 1892). 
As Graham has shown, traces of the ideal language assumption can be found in classical China as well (Graham 1989: 404). Among sinologists, Hansen can be considered as an obvious proponent of the need for an ideal language for interpreting Chinese thought. Today, traces of the ideal language assumption can be found in numerous publications. In contrast, Zhuangzi's chapter 2 (Qiwulun 《齊物論》) can be read as a critique or as a deconstruction of the ideal language assumption. ${ }^{56}$

One could deploy the notion of an ideal language to argue that each tradition has its own ideal language (this would lead to radical incommensurability). However, it is more common to argue that all traditions (can) contribute to one universal philosophy. Of course, committing oneself to one universal philosophy still leaves numerous options open. $^{57}$

Choices/prejudices with respect to the notion of language apply to particular languages as well. Major issues concerning classical Chinese include:

1. Should we assume that classical Chinese is "by and large prescriptive - a guiding discourse for practical affairs" (as both Hansen and Ames affirm) ${ }^{58}$

2. Is classical Chinese as a natural language different from modern languages only in details? Or is its function/purpose fundamentally different? (Ames and Rosemont 1998: 306).

3. Standard grammars of classical and modern Chinese are recent "inventions" and are based on the subject-predicate structure. However, a number of scholars oppose imposing a subject-predicate structure on classical Chinese statements (yan 言).

4. What kind of constraint can grammatical (more than semantic) differences place on interpretation? This would bear on issues such as the so-called mass noun hypothesis and the translation of baimafeima 白馬非馬.

The stance taken with respect to such issues would contribute to hermeneutic relativity.

Closely related to the idea of an ideal language is the belief in human (or cultural) universals, which would leave their traces in every language. In the early days of

\footnotetext{
${ }^{56}$ Zhuangzi does not oppose the use of language. He only opposes certain forms of language, namely the ideal language involving fixed meanings and rigid shifei 是非 distinctions.

${ }^{57}$ For example, Hall and Ames consider the very different approaches of Schwartz (1985) and Hansen (1992) as both examples of transcendental monism (Hall and Ames 1995: 148-49).

${ }^{58}$ Hansen (1992: 53). Ames (1994: 558).
} 
comparative philosophy, it was often taken for granted that European philosophical concepts could serve as universal categories for comparing traditions. Even today such an assumption is not uncommon, though it appears in more nuanced versions than in the past. For example, according to Smid, from the generation of Hocking to that of Neville, (American) sinologists aim to set up a set of categories that function as a universal framework. However, Neville is much more nuanced than Hocking and Northrop in that the "universal" categories are not determined prior to interpretation, but arise directly from the things that are compared. ${ }^{59}$ The quasi-universals we advocate are more surely to be constructed during the process of interpretation or intercultural philosophical dialogue and are limited to a small number of languages.

A cursory overview of the literature shows that most comparative philosophers are guilty of transcendental pretence. This means that they take for granted concepts such as know* and metaphys* and project them onto the texts/scholars to be interpreted. As Shun has stressed, there is an "obvious asymmetry in the way in which Chinese and Western philosophical traditions are brought together" (Shun 2009: 469). In some cases there are extensive discussions about the "absence" or "presence" of Western notions in classical Chinese. For example, it has been argued that the Western category of be* cannot be found in classical Chinese. The category of tru* in the sense of a property of sentences may be a similar case. Such questions are always approached from the side of European categories. The issue is rarely approached from the Chinese side, for example whether $l i$ 理 is present or absent in Western discourse.

\section{WHAT IS SHARED?}

The construction of a meta-language presupposes, inter alia, an assumption concerning what is shared across traditions. ${ }^{60}$ No matter what, something needs to be shared. One can only compare $\mathrm{X}$ and $\mathrm{Y}$ if we already have at least a minimal understanding of their respective concepts (at least in some parts of colloquial language connected to the mutual recognition of human practices). Even a "radical" difference can only be made sense of on the basis of assumptions concerning what is shared. As to what is shared, we have come across three dominant groups of

\footnotetext{
${ }^{59}$ Neville's general aim is to provide more adequate comparative categories that could be applicable to both sides. For more details about Neville's construction of comparative categories, see Smid (1990: 150-54).

${ }^{60}$ This aspect of hermeneutic relativity includes the "pre-comparative tertium" (Chakrabarty and Weber 2016: 7).
} 
proposals: shared categories, shared experiences (shared features of being human), or shared (philosophical) problems.

In both traditional and modern Western philosophy, it has been common to assume a set of basic categories (which would be universal for all humans/languages). This assumption is supported by either transcendental or empirical evidence. For example, Neville's theory of interpretation is based on the formation of basic categories, which is possible because of the same underlying transcendental reality (Smid 2009: 204). ${ }^{61}$ With the increasing influence of cognitive science on philosophy, such authors as Slingerland have made pronouncements concerning basic categories on solely empirical (naturalistic) grounds: "We are embodied animals, with a conceptual world constructed by genes and the physical-cultural environment" (Slingerland 2016: 337). Basic categories are regarded as "true" universals, which are independent of particular languages. In contrast, the kind of quasi-universals that we propose are limited to family resemblance between concepts in a few languages only.

A second possibility is that one presupposes the same everyday experiences. Shun writes: "There are, presumably, fundamental human concerns and experiences that are shared across cultures and times, such as how to confront death and hardship or how to bring about social harmony" (Shun 2016: 68). Schwartz combines "a common world of human experience" with the "universality of existential problems" and "shared problematiques" (Schwartz 1985: 13-14). Shared experiences have some similarity to the mutually recognizable human practices that we speak of, but there is greater plausibility that practices, rather than experiences, are shared, because a rather similar practice (for example butchering an ox) may bring about quite varying experiences in different traditions.

Reding suggests that different philosophical traditions (with different histories and no shared origin) react differently to "the same problems" (Reding 2004: 5), because there is a "basic unity of philosophical thinking" (3) and a "fundamental unity of cultures" $(5 \mathrm{n} 14)$. We think that it is mistaken to assume the existence of "the same problems" that can be talked about independently of particular traditions.

Other scholars locate the "same problems" in the human condition: "how to regulate social relations, how to fashion a life worth living, and how to institute good governance" (Nylan 2016: 103). The "same experiences" and the "same basic

${ }^{61}$ At an earlier stage, Hocking was more categorical: "The basic categories both of being and value are the same everywhere" (Smid 2009: 30). 
categories" can also be seen as specifications of the "same problems" of the human condition and the latter might be specified in still other ways (cf. Schwartz's "shared problematiques"). Consider as a final example the view of Zhang Longxi (1999). Although he speaks of an "enormous gap" between East and West (41), he claims that we can find "equivalences because of the basic translatability of language." People are "equal in their ability to think, to express, to communicate, and to create values" (46).

Many more examples could be given about alternative assumptions as to "what is shared." As mentioned in $\S 1$, we defend that the mutually recognizable human practices is what is most basically shared across traditions. Whether there are shared categories/concepts, common experiences, or shared (philosophical) problems cannot be presupposed in advance. Rather than that, they should be shaped as the result of comparative inquiry; that is, they are subject to the necessary preconditions mentioned in $\S 1$ and discussed in more detail in Ma and van Brakel (2016a, 2016b), including the necessary precondition that the interpreter must presuppose mutually recognizable human practices.

\section{QUASI-UNIVERSALS}

The construction of quasi-universals (including hybrid concepts and clusters of concepts) is a variable of hermeneutic relativity that is relevant at the most applied level. Having to choose quasi-universals is unavoidable, because they are needed for the construction of the meta-language of the interpreter. Because our proposed notion of quasi-universal is unique, we cannot yet discuss actual examples from the literature. The nearest to our emphasis on the crucial aspect of choice of quasiuniversals are discussions about alternative translations of Chinese characters. We have discussed many examples of alternative translations in earlier work. Here we want to make a provisional proposal of how one might go about constructing quasiuniversals. Somewhat idealized, one can discern the following sequence in building the needed meta-language:

1. Identify mutually (recognizable) shared (human) practices.

2. Identify possible quasi-universals in everyday language (on both sides).

3. Construct quasi-universals across traditions by extension of family-resemblance 
concepts on both sides; for example: $\{y u$ 欲 $\Leftrightarrow$ desire $\} .{ }^{62}$

4. Provisionally select key terms not to be translated (on both sides); for example $q i$ 氣 and "metaphys*." Some of these key terms may be dealt with in steps 5 or 6 .

5. Construct hybrid concepts to be added to the meta-language. These concepts are new concepts in the interpreter's language, but they already exist in the language to be interpreted. Such hybrid concepts can be explained in terms of English or Chinese concepts. An example of the former is: ${ }^{63}$

\{qing 情 $\} \Leftrightarrow\{\mathrm{real} / \mathrm{basic}$ facts, principles/essentials, passions, virtues, sentiments (basic instinctive feelings), desires, sensibilities, state of perfect genuineness, ultimate motives, deep convictions, authenticity, emotional response to situations, distinguishing right from wrong\}

To the left (of the sign $\Leftrightarrow$ ), there is a Chinese family-resemblance concept; to the right, a hybrid concept in English. A neologism could be chosen as a short-hand for the right-hand side; for example, by simply introducing "qing" as a new English word and claiming \{qing 情 $\Leftrightarrow$ qing (“qing” and “qing” are different words/concepts!).

Another possibility is to embed qing among a cluster of FR-concepts in classical Chinese. For example:

$\{q i n g$ 情 $\} \Leftrightarrow\{x i n$ 心, $x i n g$ 性, $y u$ 欲; $q i$ 气, $l i$ 理, $l i$ 禮; $s h i$ 事, $s h i$ 實, $s h i$ 是, cheng 誠, gan 感, huai 懷, duan 端\}

Qing is left untranslated and explained as far as possible "on its own terms." ${ }^{, 64}$ But note that the meaning of the characters listed on the right-hand side is supposedly to be grasped in English.

6. Construct family resemblances between concept clusters from both sides. ${ }^{65}$ An example is:

cluster of \{dang 當, shi 是, ran 然, zhen 真, zheng 正, cheng 誠, you 有,

\footnotetext{
${ }^{62} \mathrm{We}$ emphasize that the construction of a quasi-universal has two sides. Justifying $\{z h i \Leftrightarrow$ know* $\}$ requires showing how both know* and $z h i$ can be extended to include features of the other side.

${ }^{63}$ We do not claim that these "definitions" of qing are particularly good. It merely serves as an example to give an idea of what kind of thing a hybrid concept is. Similar proposals go back at least as far as Richards (1932).

${ }^{64}$ Probably more characters are listed than any interpreter might want to use in explaining the embedment of qing. Different interpreters may select a different subset or add other characters, in particular if they focus on different texts.

${ }^{65}$ Various authors have advocated focusing on concept clusters instead of single concepts; e.g. Rosemont (2012: 17-21). Perkins correctly remarks that clusters cannot be completely disambiguated (Perkins 2016: 189).
} 
shi 實, xin 信, ...\} $\Leftrightarrow$ cluster of $\{$ true, being so, right, correct, fitting, genuine, trustworthy, sincere, ...\}

7. Explain any remaining characters/concepts in terms of the above.

The seven steps above are suggestions of how to go about constructing quasiuniversals. In future publications we expect to work out this proposal in more detail.

\section{AFTERWORD: SHIFEI 是非}

The fact of hermeneutic relativity (the implicit choices or "prejudices" of the interpreter) raises the meta-question of how to assess alternative options. Although often suppressed, there seem to be no "rational," "fixed," or "precise" rules guiding such an assessment. Hall and Ames use the duck-rabbit image to make sense of their disagreement with Paul and Martin (Hall and Ames 1991: 343). This reminds us of Zhuangzi's critique of Mohists and Ruists in the second chapter of the Zhuangzi:

故有儒墨之是非, 以是其所非而非其所是

..., then we have the rights and wrongs of the Confucians and the Mo-ists.

What one calls right the other calls wrong; what one calls wrong the other calls right. (transl. Watson 1968)

Each interpreter will "argue" that his/her interpretation is better than that of others, but neither side can have an absolute standard. However, we do not conclude that there is neither shi nor fei as Guo Xiang 郭象 perhaps does on behalf of Zhuangzi:

\section{則無是無非無好無惡者 (Guo 2011: 122)}

... then there is neither shi nor $f e i$, neither like nor dislike ...

The simple fact of using the words shi and $f e i$ in classical texts entails that there must already be certain shared opinions about their (everyday) meaning before any conclusion or speculation concerning a shifei conflict or impasse can be achieved (either by Zhuangzi or by a later commentator). As Zhuangzi seems to acknowledge and to underscore in practice: Speaking is not the same as breathing. Meanings are neither fixed nor determined (weiding 未定); nevertheless, unfixed meanings are still meanings.

In the commentary to his first translation of the Qiwulun, Graham draws attention to the distinction of yinshi 因是 and weishi 為是, which he translates as “adaptive shi" and "contrived shi" (Graham 1969: 143). Yin is "to base one's actions on the changing situation, to adapt to circumstances without imposing fixed principles." In 
contrast, wei is "to act on inflexible principles, forcing one's will against the spontaneous course of things" (143-44). Hence, Graham suggests yin and wei point to opposite kinds of shi. Although we are not completely convinced by Graham's choice of these terms as "contrasting" variants of shi, we think that Graham is right to say that Zhuangzi argues that shifei clashes are usually of the "contrived" type (weishi). We intend to argue that clashes are also possible at the level of focusing on the specific situation at hand (yinshi). However, the (pragmatic) possibility of dialogue remains open - though could be refused. Further, we suggest that we make a distinction between positions formulated in terms of beliefs/propositions (which have a truth value) and stances that include not only beliefs but also emotions and other non-cognitive matters. A "conflict" between different stances is of a pragmatic nature, which avoids a clash in the strict sense of either contradicting one another, or lacking mutual understanding. Hence, we advocate a pluralism that allows "incomparable" interpretations without having to endorse the idea that "anything goes."

Acknowledgement: We thank two anonymous reviewers of an earlier version of this essay for many insightful and helpful comments.

\section{References}

Allinson, Robert E. 2003. "Intercultural hermeneutics." In Encyclopedia of Chinese Philosophy, edited by Antonio S. Cua, 315-320. New York and London: Routledge.

Ames, Roger T. 1994. "Review of Hansen (1992)." Harvard Journal of Asiatic Studies 54 (2):553-561.

Ames, Roger T. 2004. "A response to critics." Dao: A Journal of Comparative Philosophy 3 (2):281-298.

Ames, Roger T. 2005. "Getting past the eclipse of philosophy in world sinology: A response to Eske Møllgaard." Dao: A Journal of Comparative Philosophy 4 (2):347-352.

Ames, Roger T. 2011. Confucian Role Ethics: A vocabulary. Hong Kong: The Chinese University Press.

Ames, Roger T., and David L. Hall. (trans1.) 2003. Dao De Jing-Making This Life Significant-A philosophical translation. New York: Ballantine Books.

Ames, Roger T., and Henry Rosemont. (transl.) 1998. The Analects of Confucius: A philosophical translation. New York: Ballantine (Random House). 
Berthrong, John H. 2006. "To catch a thief: Zhu Xi (1130-1200) and the hermeneutic art." Jounal of Chinese Philosophy 33 (Book Supplement Series):145-159.

Billeter, Jean François. 1998. "Stopping, seeing and language: an interpretation of Zhuangzi's Qiwulun (Mark Elvin, transl.)." East Asian History (15/16):1-32.

Brown, Nahum, and William Franke, eds. 2016. Transcendence, Immanence, and Intercultural Philosophy. London: Palgrave-Macmillan.

Chakrabarti, Arindam, and Ralph Weber, eds. 2016. Comparative Philosophy without Border. London: Bloomsbury.

Chao, Yuen Ren (Zhao, Yuanren) 趙元任. 1969. "Dimensions of fidelity in translation with special reference to Chinese." Harvard Journal of Asiatic Studies 29:109-130.

Cheng, Chung-ying. 2000. "Confucian onto-hermeneutics: Morality and ontology." Jounal of Chinese Philosophy 27 (1):33-68.

Cua, Antonio S., ed. 2003. Encyclopedia of Chinese Philosophy. New York and London: Routledge.

Frege, Gottlob. 1892. "Über Sinn und Bedeutung." Zeitschrift für Philosophie und philosophische Kritik 100:25-50.

Frisina, Warren G. 2016. "Thinking through Hall and Ames: On the art of comparative philosophy." Dao: A Journal of Comparative Philosophy 15:563-574.

Gadamer, Hans-Georg. 1989. Truth and Method. New York: Continuum (2004). Second revised edition, corresponding to the 5th German edition in Gadamer's Gesammelte Werke.

Gardner, Daniel. (transl.) 1990. Learning to Be a Sage. Berkeley: University of California Press.

Goodman, Nelson. 1978. Ways of Worldmaking. Indianapolis: Hackett.

Graham, A. C. 1969/70. "Chuang-Tzu's essay on seeing things as equal." History of Religions 9 (2/3):137-159.

Graham, Angus C. 1989. Disputers of the Tao: Philosophical argument in ancient China. Chicago: Open Court.

Guo, Xiang 郭象. 2011. "Commentary on the Zhuangzi." In Zhuangzi Zhusu 《莊子注疏》. Beijing: Zhonghua Shuju.

Hall, David L., and Roger T. Ames. 1987. Thinking Through Confucius. Albany: SUNY Press.

Hall, David L., and Roger T. Ames. 1991. "Against the greying of Confucius: Responses to 
Gregor Paul and Michael Martin." Journal of Chinese Philosophy 18 (3):333-347.

Hall, David L., and Roger T. Ames. 1995. Anticipating China: Thinking through the narratives of Chinese and Western culture. Albany: SUNY Press.

Han, Christina. 2013. "Between poetry and philosophy: The Neo-Confucian hermeneutics of Zhu Xi's nine bends poem." Asian Philosophy 23 (1):62-85.

Hansen, Chad. 1992. A Daoist Theory of Chinese Thought. A philosophical interpretation. New York: Oxford University Press.

Hansen, Chad. 2005. "Reading with understanding: interpretive method in Chinese philosophy." Dao: A Journal of Comparative Philosophy 4 (2):341-346.

Jenco, Leigh. 2016. "Methods from within the Chinese tradition." In Chinese Philosophy Methodologies, edited by Sor-hoon Tan, 273-288. London: Bloomsbury.

Li, Jingde (黎靖德), ed. 1986. Zhuxi yulei. [朱子語類 Classified Conversations of Master $Z h u]$. Beijing: Zhonghua shuju.

Li, Xiaofan Amy. 2015. "The notion of originality and degrees of faithfulness in translating classical Chinese: Comparing translations of the Liezi." Early China 38:109-128.

Li, Yinghua. 2010. "Review of Xiaogan Liu, Interpretation and Orientation (2009)." Dao: A Journal of Comparative Philosophy 9:367-370.

Lin, Shuen-Fu. 2003. "Transforming the Dao: A critique of A.C. Graham's translation of the inner chapters of the Zhuangzi." In Hiding the World in the World: Uneven Discourses on the Zhuangzi, edited by Scott Cook. Albany: State University of New York Press.

Littlejohn, Ronnie. 2016. "On what it means to "let a text speak for itself?": Philosophizing with classical Chinese texts." In Chinese Philosophy Methodologies, edited by Sorhoon Tan, 75-90. London: Bloomsbury.

Ma, Huijian. 2007. "Jin Di’s and Eugene A. Nida’s translation theories." Babel 53 (2):98111.

Ma, Lin. 2004. "Review of Pan Derong (2003)." Dao: A Journal of Comparative Philosophy $3(2): 343-347$.

Ma, Lin. 2014. "A Zhuangzian Response to Heidegger's Mitsein." Journal of Chinese Philosophy 41 (3-4):487-502.

Ma, Lin, and Jaap van Brakel. 2013. "On the conditions of possibility for comparative and intercultural philosophy." Dao: A Journal of Comparative Philosophy 12: 297-312.

Ma, Lin, and Jaap van Brakel. 2016a. Fundamentals of Comparative and Intercultural 
Philosophy. Albany NY: State University of New York Press (forthcoming).

Ma, Lin, and Jaap van Brakel. 2016b. "A Theory of Interpretation for Comparative and Chinese Philosophy." Dao: A Journal of Comparative Philosophy 15:575-589.

Ma, Lin, and Jaap van Brakel. 2016c. "Revisiting Wittgenstein on family resemblance and colour(s)." Philosophical Investigations 39 (3):254-280.

Makeham, John. 2006. "A new hermeneutical approach to early Chinese texts: The case of the Analects." Jounal of Chinese Philosophy 33 (Book Supplement Series):95-108.

Martin, Michael R. 1990. "Book Review of Hall and Ames (1987)." Jounal of Chinese Philosophy 17 (4):495-503.

Martinich, A.P., and Yang Xiao. 2010. "Ideal interpretation: The theories of Zhu Xi and Ronald Dworkin." Philosophy East and West 60 (1):88-114.

Møllgaard, Eske. 2005. "Eclipse of reading: On the 'philosophical turn' in American sinology." Dao: A Journal of Comparative Philosophy 4 (2):321-340.

Neville, Robert Cummings. 1995. Normative Cultures. Albany: State University of New York Press.

$\mathrm{Ng}$, On-cho. 2007. "Toward a hermeneutic turn in Chinese philosophy: Western theory, Confucian tradition, and Cheng Chung-ying's onto-hermeneutics." Dao: A Journal of Comparative Philosophy 6:383-395.

Ni, Peimin. 2016. "Gongfu method in the Analects and its significance beyond." In Chinese Philosophy Methodologies, edited by Sor-hoon Tan, 127-142. London: Bloomsbury.

Nylan, Michael. 2016. "Academic silos, or "What I wish philosophers knew about early history in China." In Chinese Philosophy Methodologies, edited by Sor-hoon Tan, 91114. London: Bloomsbury.

Olberding, Garret P.S. 2012. Dubious Facts. Albany: State University of New York Press. Pan, Derong. 2003. Language, Hermeneutics, and Tradition: On the transformation of Chinese hermeneutic tradition in the contemporary world [in Chinese]. Shanghai: Shanghai Yiwen Chubanshe.

Pan, Derong, and Qifu Peng. 2006. "On Zhu Xi's theory of interpretation." Journal of Chinese Philosophy 33 (Book Supplement Series):135-143.

Paul, Gregor. 1991. "Reflections on the usage of the terms 'logic' and 'logical'." Journal of Chinese Philosophy 18 (1):73-87.

Peng, Ting-ting. 2015. "A comparative study of literal translation and free translation of an extended bridge - from Yan Fu's translation criterion 'faithfulness, expressiveness, and elegance'." Frontiers of Literary Studies in China 9:581-615. 
Perkins, Franklin. 2016. "Metaphysics and methodology in a cross-cultural context." In Chinese Philosophy Methodologies, edited by Sor-hoon Tan, 183-198. London: Bloomsbury.

Pfister, Lauren F. 2006. "Editor's introduction." Journal of Chinese Philosophy 33 (Book Supplement Series):3-24.

Putnam, Hilary. 2002. The Collapse of the Fact/Value Dichotomy. Cambridge: Harvard University Press.

Reding, Jean-Paul. 2004. Comparative Essays in Early Greek and Chinese Rational Thinking. Aldershot: Ashgate.

Richards, Ivor Armstrong. 1932. Mencius on the Mind: Experiments in multiple definition. London: Curzon (1997).

Roetz, Heiner. 1993. "Validity in Chou thought: on Chad Hansen and the pragmatic turn in Sinology." In Epistemological Issues in Classical Chinese Philosophy, edited by Hans Lenk and Gregor Paul, 69-113. New York: SUNY Press.

Rosemont, Henry. 2012. A Reader's Companion to the Confucian "Analects". Honolulu: University of Hawaii Press.

Schwartz, Benjamin I. 1985. The World of Thought in Ancient China. Cambridge MA: Harvard University Press.

Shun, Kwong-loi. 2009. "Studying Confucian and comparative ethics: Methodological reflections." Journal of Chinese Philosophy 36 (3):455-78.

Shun, Kwong-loi. 2016. "Methodological reflections on the study of Chinese thought." In Chinese Philosophy Methodologies, edited by Sor-hoon Tan, 57-74. London: Bloomsbury.

Slingerland, Edward. 2016. "Interdisciplinary methods in Chinese philosophy: Comparative philosophy and the case example of mind/body holism." In Chinese Philosophy Methodologies, edited by Sor-hoon Tan, 323-351. London: Bloomsbury.

Smid, Robert W. 2009. Methodologies of Comparative Philosophy: The pragmatist and process traditions. Albany: SUNY Press.

Tan, Sor-hoon. 2016. "Introduction: Why methodology matters." In Chinese Philosophy Methodologies, edited by Sor-hoon Tan, 1-33. London: Bloomsbury.

Tan, Xiaoli, and Tianyuan Huang. 2015. "Translating Chinese philosophy on its own terms: an interview with Professor Roger T. Ames." Asia Pacific Translation and Intercultural Studies 2 (2):139-149.

van Brakel, Jaap, and Lin Ma. 2015. "Extension of family resemblance concepts as a 
necessary condition of interpretation across traditions." Dao: A Journal of Comparative Philosophy (4):475-497.

Watson, Burton. 1968. The Complete Works of Chuang Tzu. New York: Columbia University Press.

Zhang, Longxi. 1992. The Tao and the Logos: Literary Hermeneutics, East and West. Durham and London: Duke Universit Press.

Zhang, Longxi. 1999. "Translating cultures: China and the West." In Chinese Thought in a Global Context: A dialogue between Chinese \& Western philosophical approaches, edited by Karl-Heinz Pohl, 29-46. Leiden: Brill.

Zheng, Shuhong. 2017. "Above the literal sense: Hermeneutical rules in Zhu Xi, Eckhart, and Augustine." Dao: A Journal of Comparative Philosophy 16:253-276.

Ziporyn, Brook. 2013. Beyond Oneness and Difference: Li and Coherence in Chinese Buddhist Thought and Its Antecedent. Albany: State University of New York Press. 